\title{
The first 500 patients with sacral anterior root stimulator implants: general description
}

\author{
G S Brindley MD FRCP FRS \\ Spinal Injuries Unit, Royal National Orthopaedic Hospital, Stanmore HA7 4LP, UK.
}

The first 500 patients to have sacral anterior root stimulators implanted for bladder control are described. Of 479 survivors, 424 were using their stimulators when last followed up between 3 months and 16.1 years (mean 4 years) after implantation.

Keywords: sacral anterior root stimulator; bladder; spinal cord injury.

\section{Introduction}

The sacral anterior root stimulator was developed by experiments on baboons in the MRC Neurological Prostheses Unit in London during the years 1969-77. The first micturition driven by a stimulator implanted into an animal was achieved in February 1972. ${ }^{1-3}$ Similar work was done several years later in San Francisco. The San Francisco group reported micturition driven by external electrical stimulator in acute experiments in dogs in $1978,{ }^{4}$ but by implant not until 1982. ${ }^{5}$ The first human sacral anterior root stimulator was implanted in London in $1976,{ }^{6}$ but gave no useful micturition. The second and third were implanted in $1978 .{ }^{6}$ They were successful, and one of them is still in use in 1994. Somewhat similar implants were developed in San Francisco a few years later. Literature on the San Francisco implants is scanty. Twenty-three of them have been reported in publications, ${ }^{7.8}$ but it seems that very few more than these 23 have been implanted. The present paper reviews the first 500 patients with implants of the London design. ${ }^{6-9-48}$ The 500th was implanted in February 1992.

It is usual to cut the sacral posterior roots at the time of implantation of electrodes on the anterior. This practice was begun in 1981 to improve continence. ${ }^{10}$ It was not at first done in all patients, and was restricted to the S2 and S3 roots. The benefit to the upper urinary tracts of doing it in all or nearly all patients, and of including the S4 roots, was first pointed out by $\mathrm{Dr} D$ Sauerwein in 1986, and it was he ${ }^{17}$ who first achieved satisfactory posterior rhizotomy in S4, where it is more difficult than in S2 and S3.

\section{Sources of information}

The largest source of information is a questionnaire sent out in 1991 to all centres in which sacral anterior root stimulators have been implanted. The questionnaire was short, and designed to be easily answered. It asked for sex, date of birth, date of implantation, date of most recent follow up, whether the patient had died and if so the cause of death, whether the implant was in use at the most recent follow up, any possible harmful effects of use of the implant on the upper urinary tract, whether the implant became infected, and any failures in the implant. No questions were asked about benefits of the implant, for reasons that will be considered in the discussion.

By the end of 1992 every centre had answered. I am very grateful to those who have helped me in this way. They are listed in the Appendix. Many centres have provided further information in 1993 and 1994, and some have kindly sent information that I did not directly request, but was very glad to have. 
Some of the facts reported were learned by my talking to the patients, and examining and investigating them; I have been involved in the clinical management of 241 of the 500 patients, and have at some time talked with all these and 43 others. The major centres of implantation are listed in Table I. During the last 13 years I have visited all the major centres except Berlin (10 of them were visited five or more times each, and three others four times each), and 22 of the 28 minor centres.

The cases reported by each centre have been compared with the sales records, classified by year and destination, provided by the manufacturers (Finetech Medical Ltd). The agreement is close enough to prove that the 500 cases here reported are very nearly the real first 500 . The number accidentally omitted, and hence accidentally replaced by patients whose serial numbers should properly be just over 500 , is unlikely to be as many as five.
A little information is taken from publications in which patients are listed and can be identified one-to-one with those given in an answer to my questionnaire. ${ }^{11-13,16,18.33,34.47}$ From reference 44, supplementary information about the Le Mans and Bordeaux patients was obtainable, even though these patients were not tabulated as individuals.

In 1992, Dr P E V van Kerrebroek sent out a much longer questionnaire than mine to the same centres. He received replies from 23 centres, but the largest German centre, the second-largest Dutch centre and all British centres except Hexham failed to reply. His analysis of the replies has been published..$^{40}$ It covers 184 patients, of whom 165 come within the first 500 .

The total follow up time for all 500 patients is 2033.5 years. If implants that have never been used and the final period of non-use of implants that have ceased to be used are subtracted, the figure becomes 1922.9 years.

Table I Major centres (defined as centres that had done at least five implantations by February 1992)

\begin{tabular}{|c|c|c|c|c|}
\hline Centre & Began & Men & Women & Total \\
\hline Maudsley Hospital, London & 1976 & 38 & 14 & 52 \\
\hline Sheffield & 1981 & 25 & 7 & 32 \\
\hline Christchurch, NZ & 1982 & 6 & 3 & 9 \\
\hline Edinburgh \& Glasgow & 1982 & 9 & 2 & 11 \\
\hline Oxford \& Stoke Mandeville & 1983 & 30 & 14 & 44 \\
\hline Cardiff & 1983 & 13 & 1 & 14 \\
\hline Le Mans & 1984 & 21 & 9 & 30 \\
\hline Maida Vale \& Stanmore & 1984 & 7 & 4 & 11 \\
\hline Bad Haering \& Innsbruck & 1985 & 3 & 14 & 17 \\
\hline Copenhagen & 1985 & 7 & 0 & 7 \\
\hline Melbourne & 1985 & 5 & 0 & 5 \\
\hline Bristol \& Odstock & 1986 & 6 & 0 & 6 \\
\hline Bad Wildungen & 1986 & 26 & 86 & 112 \\
\hline Stoke-on-Trent \& Southport & 1986 & 10 & 0 & 10 \\
\hline Bordeaux & 1987 & 8 & 6 & 14 \\
\hline Sydney & 1987 & 4 & 2 & 6 \\
\hline Enschede & 1987 & 8 & 4 & 12 \\
\hline Bremen & 1988 & 0 & 6 & 6 \\
\hline Schwelm & 1988 & 1 & 12 & 13 \\
\hline Nijmegen & 1989 & 6 & 11 & 17 \\
\hline Berlin & 1989 & 3 & 4 & 7 \\
\hline Montpellier & 1990 & 1 & 5 & 6 \\
\hline Barcelona & 1990 & 0 & 5 & 5 \\
\hline 28 minor centres & various & 34 & 20 & 54 \\
\hline Total & & 271 & 229 & 500 \\
\hline
\end{tabular}




\section{The operations}

Table II shows the number of implantations in each year from 1976 to 1991 . The increase year by year has been slow, but it has continued almost without interruption.

Table III shows the kinds of implant used.

Table IV shows what posterior rhizotomy (within the range S2-5) was attempted at the time of implantation, and whether further deafferentation was done later.

In all the 12 patients whose primary deafferentation was at the conus, and in 11 other patients, the electrodes were implanted extradurally in the sacrum. In all or most of the other 477 patients, they were implanted intrathecally at the level of the fifth lumbar vertebra and last intervertebral disc.

\section{The patients}

Tables V and VI classify the patients by age and lesion.

Of the 498 spinal cord lesions, 55 were described as incomplete and 323 as complete. For 173 of them no statement was made about completeness. Among the 55 with lesions known to be incomplete, 25 had sparing of posterior column function only, and 30 , including all the nine with multiple sclerosis, retained some pain sensitivity. In 14 of the 30 with spared pain sensitivity, four-, six- or eight-channel implants were used.

\section{Total time of use}

The aggregate follow up of the 500 patients, from the date of operation to when they

Table II Number of implantations in each year

\begin{tabular}{lccc}
\hline Year & Number & Year & Number \\
\hline 1976 & 1 & 1984 & 21 \\
1977 & 0 & 1985 & 31 \\
1978 & 2 & 1986 & 37 \\
1979 & 4 & 1987 & 53 \\
1980 & 2 & 1988 & 50 \\
1981 & 2 & 1989 & 76 \\
1982 & 9 & 1990 & 82 \\
1983 & 17 & 1991 & 104 \\
First 6 weeks & & & 9 \\
$\quad$ of 1992 & & & \\
\hline
\end{tabular}

Table III Kinds of sacral anterior root stimulator

\begin{tabular}{lc}
\hline Kind & Number \\
\hline Intrathecal, 1-channel & 3 \\
Intrathecal, 2-channel & 15 \\
Intrathecal, 3-channel & 405 \\
Intrathecal, 4-channel & 10 \\
Intrathecal, 6-channel & 1 \\
Intrathecal, 8-channel & 3 \\
Intrathecal, channels unknown & 4 \\
Extradural, 3-channel & 22 \\
Extradural, 4-channel & 1 \\
Kind unknown & 36 \\
Total & 500 \\
\hline
\end{tabular}

were last seen or telephoned, is 2033.5 years. Subtracting all periods of non-use (including those followed by re-use), the total time of use is 1897.1 years.

\section{Results}

Benefits

This paper would be unbalanced if it said nothing about what patients gain from having a sacral anterior root stimulator and sacral posterior rhizotomy. However, since the questionnaire asked nothing about benefits, consideration of these benefits is deferred to the discussion, where relevant publications are cited for each benefit.

\section{Infections}

Four stimulators became infected (apparently at the time of implantation) and had to be explanted completely. In one of the four patients new electrodes were later implanted extradurally, and the new stimulator works well.

Three of these infections were acute and demanded early explantation, but in one patient the stimulator was in use for nearly 2 years before it had to be explanted.

In two patients it became evident a few weeks after the operation that there was infection around the receiver block, but it seemed that there was none elsewhere. An incision was made near the midaxillary line and the cables cut there. Then the receiver pouch was opened, and the receiver block with at least $12 \mathrm{~cm}$ of each cable still 
Table IV Deafferentation

\begin{tabular}{lrc}
\hline $\begin{array}{l}\text { Attempted primary } \\
\text { deafferentation }\end{array}$ & Number & $\begin{array}{c}\text { Number who subsequently had } \\
\text { secondary deafferentation }\end{array}$ \\
\hline Complete near root exits & 251 & 7 \\
Incomplete near root exits & 79 & 13 \\
Complete at conus & 12 & 0 \\
Complete at ganglia & 9 & 2 \\
None & 64 & 12 \\
Unknown & 85 & 5 \\
Total & 500 & 39 \\
\hline
\end{tabular}

Table V Age at operation

\begin{tabular}{lc}
\hline Age at operation & Number \\
\hline 14 & 1 \\
$15-17$ & 8 \\
$18-19$ & 11 \\
$20-29$ & 183 \\
$30-39$ & 133 \\
$40-49$ & 80 \\
$50-59$ & 29 \\
$60-69$ & 3 \\
Unknown & 52 \\
Total & 500 \\
\hline
\end{tabular}

attached was removed. The remaining part of the implant has remained uninfected. It will doubtless be possible to fit new receiver blocks, but this had not yet been done when I last received information.

In five patients a part of the receiver became exposed either by dehiscence of the wound within the first few days or by ulceration later, in circumstances where it seemed probable that the cause of the dehiscence or ulceration was not infective. These were managed in various ways. In none of the five was the whole implant lost, and in four of them it is now in use.

Ninety-five operations have been done to remedy faults in implants, as described in detail in references 46 and $49 ; 75$ of these were repair procedures, either replacing receiver blocks or rejoining broken cables, and 20 were implantations of new extradural stimulators. Two of the repair operations were followed by infection of the new receiver block. The infected block was removed, and after a few months replaced. Both these stimulators are now in use again.

One new extradural stimulator, implanted to replace a failed intrathecal one, became infected. It was completely removed, and another new one will probably

Table VI Sex and lesion

\begin{tabular}{lrrr}
\hline Lesion & Men & Women & Total \\
\hline Traumatic, cervical & 64 & 58 & 122 \\
Traumatic, thoracic & 141 & 108 & 249 \\
Traumatic, lumbar & 3 & 4 & 7 \\
Neoplasm (all thoracic) & 2 & 7 & 9 \\
Transverse myelitis & 5 & 4 & 4 \\
Multiple sclerosis & 57 & 4 & 9 \\
Meningomyelocoele & & 1 & 1 \\
Unspecified cord lesions & & 1 & 1 \\
Cerebral palsy & 271 & 229 & 58 \\
No known CNS lesion & & 1 & 500 \\
Total & & & \\
\hline
\end{tabular}

'No known CNS lesion' refers to a women who is healthy except for inability to empty her bladder. 
soon be put into the patient. With the four infected at primary implantation, it brings to five $(1 \%)$ the total number of stimulators lost by infection.

One stimulator which never showed any sign of being infected was explanted, for reasons unknown to me.

\section{Present state of the patients}

Table VII shows the status of the implant in each patient at the last known follow up.

\section{Deaths}

The causes of 16 of the 21 deaths (sex and age in brackets for each) are recorded as suicide (five: F42, F30, F42, M52, F64); multiple sclerosis (two: F40, F56); cardiovascular accident (one: F56); coronary thrombosis (one: M52); septicaemia (two: $M$ age unknown, M22); carcinomatosis, primary in the bladder (one: M42); amyloidosis from osteomyelitis (one: M55); carcinoma of breast (one: F39); renal failure (one: M34); hepatitis (one: M55). Of the two deaths from septicaemia, one followed an operation to remove kidney stones, from which the patient already suffered before he had the stimulator implanted. For five deaths (men aged 39, 43, 50, 51 and 69) the cause was not reported to me, except that for one of them (M43) the death was said to be 'unrelated to the stimulator'.

Table VII State of patient at last known follow up

\begin{tabular}{lc}
\hline Situation at last known follow up & Number \\
\hline $\begin{array}{l}\text { Stimulator in use for micturition } \\
\quad \text { (and in the majority for }\end{array}$ & 411 \\
$\quad$ defaecation also) & \\
Stimulator in use for defaecation & 13 \\
$\quad$ only & 6 \\
Stimulator explanted & 2 \\
Stimulator awaiting repair & 45 \\
Stimulator believed to be intact, & \\
$\quad$ but not used & 21 \\
Patient dead & 2 \\
No known follow up & 500 \\
Total
\end{tabular}

\section{Patients who do not use their implants}

Table VIII shows the reasons given for non-use in the 45 patients whose implants are intact but not used.

In just one of the 28 patients with inadequate implant-driven micturition, the responses of the bladder to sacral root stimulation were good, and the large residual volumes were attributed to detrusorsphincter dyssynergia. In the other 27 , the defective micturition is known or believed to be due mainly to weak detrusor responses. In four of these 27 patients, and also in four of the 21 patients who died, the detrusor responses were good at first but deteriorated after some years. ${ }^{46}$ In most of the remaining patients with weak detrusor responses, they have been weak since the 10 th day after the operation or earlier, and these implants have never worked well, though some of them were used for a time.

Methods of bladder management in the patients who do not use their implants are shown in Table IX.

Table VIII Reasons for non-use

\begin{tabular}{lc}
\hline Reasons for non-use & Number \\
\hline $\begin{array}{l}\text { Implant-driven micturition } \\
\text { inadequate }\end{array}$ & 28 \\
Attempts to use stimulator are & 6 \\
$\quad$ painful & 3 \\
Autonomic dysreflexia & 8 \\
No information & 45 \\
Total & \\
\hline
\end{tabular}

Table IX Bladder management in patients who do not use their implants

\begin{tabular}{lc}
\hline Method & Number \\
\hline Intermittent self catheterisation & 15 \\
Intermittent catheterisation by & 2 \\
$\quad$ helper & 4 \\
Urethral indwelling catheter & 1 \\
Suprapubic indwelling catheter & 2 \\
Straining and suprapubic pressure & 1 \\
Diversion (cystectomy for & \\
$\quad$ carcinoma) & 20 \\
Unknown & 45 \\
Total & \\
\hline
\end{tabular}




\section{Changes in the upper urinary tracts}

It is well known that the state of the upper urinary tracts can improve greatly after sacral posterior rhizotomy and implantation of a sacral anterior root stimulator. ${ }^{10,14,24,34,39,40,44,45,48}$ It remains interesting to consider whether the upper tracts can also deteriorate after such implantation. The questionnaire specifically asked about such deterioration, as well as about deaths. The patient who died of renal failure is a gross example of such deterioration.

Eleven other cases of deterioration were reported. One of these was of unilateral grade 1 ureteric reflux without upper tract dilatation. The other 10 were of upper tract dilatation seen in intravenous urography or renal ultrasound examination. In three cases this was reported to have been transient. In two cases it was still present 6 and 4 years later, without deterioration of renal function. In five cases the duration was not reported.

Ten of the 12 patients whose upper tracts deteriorated had incomplete deafferentation or none. The two who had been completely deafferented had only slight and transient deterioration.

Renal function was reported as worse in only one patient other than the one who died of renal failure. This patient's sacral anterior root stimulator was implanted, with posterior rhizotomy of S3 but not S2 or S4, in 1984. In 1985 he was admitted to a spinal injuries unit with an acute illness due to urinary infection. His creatinine clearance was found to be severely impaired $(16 \mathrm{ml} / \mathrm{min})$. He had an indwelling catheter for 7 months, and then resumed use of the implant. His creatinine clearance slowly improved, and was $49 \mathrm{ml} / \mathrm{min}$ in 1988. Renal ultrasound examination in 1990 showed small kidneys, but no hydronephrosis. In June 1994 he was using his implant for micturition and defaecation, was continent, and regarded himself as healthy.

Of the 10 patients for whom radiological but not biochemical signs of upper tract deterioration were reported, one is among the 21 listed above as having died (aged 42 from carcinomatosis, primary in the bladder). The other nine were in good health when last seen except that in one of them stones were found in the left kidney at the last routine radiological examination, $5 \frac{1}{2}$ years after implantation of his stimulator. Seven of these nine patients use their implants, one has an indwelling catheter, and one does intermittent self catheterisation.

\section{Need for secondary deafferentation}

Some early patients did not have full sacral posterior rhizotomy because its benefits and practicability were not yet understood, and in a few later patients a reasoned decision was made not to do it. Table IV shows that in 25 of 143 patients with known nondeafferentation or incomplete deafferentation, a decision was later made to cut the posterior roots at the conus medullaris.

When a surgeon attempts to cut posterior roots close to the spinal cord and spare the anterior roots, he can be sure that he has done what he attempted. When he attempts the same near the root exits, he usually succeeds, but never can be quite sure that he has succeeded. Table IV shows that among 251 patients on whom complete deafferentation near the root exits was attempted and the surgeon was not aware at the time that he had failed to achieve it, seven nevertheless needed further deafferentation.

\section{Discussion}

\section{Why were no questions asked about benefits?}

To ask about benefits would have made the task of answering the questionnaire much more difficult. Dr van Kerrebroek's experience with a questionnaire that asked about benefits, and was therefore much longer than mine ${ }^{40}$ makes it almost certain that some centres would not have answered.

There are also grounds for doubting whether statistics of benefit obtained by questionnaire would be of much value. Continence provides an illustration of the difficulty. All but three of the 96 patients in whom full sacral posterior rhizotomy was attempted and whom I know well were entirely freed from reflex incontinence as long as the bladder remained uninfected. The three exceptions all subsequently had 
secondary deafferentation and then became free from reflex incontinence. However, many patients whose bladders are areflexic when uninfected acquire a reflex-like incontinence, probably depending on autonomic plexuses in the pelvis, during urinary infections. Should they be judged continent or incontinent? I say continent, provided that they are usually free from infection (as nearly all of them are) and free from significant stress incontinence; but the opposite opinion is legitimate. It would therefore be difficult to ensure that all centres used the same criteria of continence.

\section{What are the benefits?}

I give a list, citing those references that give information relevant to each item.

1 Improvement in the degree of continence, absolute continence being often achieved. ${ }^{6,9}, 10,11,14,15,21,23,24,25,27,30,32,33$. $36,39,44$

2 Great improvement in bladder capacity ${ }^{6,9,10,44}$ and compliance, ${ }^{24,27,32-34,44,48}$ where this was bad preoperatively.

Benefits 1 and 2 are wholly or mainly due to the posterior rhizotomy. They are very probably permanent (reference 15 and all subsequent observations known to me).

3 Abolition or diminution in upper tract dilatation and improvement in renal function. ${ }^{14,24,34,39,40}$ These are probably mainly due to the improvement in compliance.

4 Abolition of high-pressure ureteric reflux. ${ }^{10,24,40}$ This can be done immediately in some patients, because the voiding pressure can be adjusted by altering the stimulus parameters until it is below that at which reflux occurs.

5 Lowering the residual urine volume. ${ }^{6.9-11,15,20,27,30,32,33,36,40,42}$

6 Great reduction of active DSD, passive DSD remaining unchanged. ${ }^{15}$

7 Fewer urinary tract infections. 10,11. $20,21,24,32,40,44$

8 Abolition of autonomic dysreflexia triggered from bladder or bowel. ${ }^{15,20,24,32,40}$

9 Implant-driven defaecation or implantassisted manual evacuation, reducing the time that the patient needs to spend on bowel management. ${ }^{10,12,21,22,24,30,39,40}$

10 Abolition of episodes of severe constipation. ${ }^{22,29}$

11 Penile erection driven by the implant. ${ }^{10,11,14,15,21,24,30,33,39,40}$

12 Treatment of stress incontinence by continuous low-voltage stimulation, which activates the rhabdosphincters without raising the bladder pressure..$^{6,9,10}$

\section{Balancing benefit against risk of harm}

Deterioration of the upper urinary tracts has been reported in only two patients among the 365 who were or may have been fully deafferented, and in these two it was slight and transient. Among the 135 patients who were not deafferented or were incompletely deafferented there were indeed 10 with upper tract deterioration, of whom two had impaired renal function and one died of it; but this may be fewer than would have been expected if their urinary tracts had continued to be managed by the nonimplant methods that they were using before their operations.

Of the 479 surviving patients, 424 were using their stimulators at last known follow up and 53 were known not to be using them. It is likely that all the 424 users were pleased with what the operation had done for them. I have never known a user who was on balance displeased, or seen any mention in the literature of such a person. What of the non-users? They are not necessarily in a worse state as a result of their operations, and many are in a clearly better state, because they are continent on intermittent self catheterisation where formerly they were incontinent. Among the first 50 patients (none of whom had complete deafferentation), six were non-users in 1986; four of these regretted having had the operation, but two did not. ${ }^{10}$ I can find no other published statement about satisfaction and dissatisfaction among non-users, but among the first 500 patients there are 20 fully deafferented non-users, of whom seven are personally well known to me. Five of these seven are pleased, on balance, with what the operation has done for them. The other two are displeased, but the wife of one 
of them (a man with multiple sclerosis) says that she regards his present continence and former incontinence as fully justifying the operation.

Does complete posterior rhizotomy of S2 to S5 always cause complete detrusor areflexia?

Reference 15 reviews some of the published evidence that the Bell-Magendie 'law' that anterior spinal roots are motor and posterior are sensory is not exactly true, and that in many people some at least of the anterior roots contain some sensory fibres and some at least of the posterior roots contain some motor fibres. Nevertheless it seems that section of the sacral posterior roots at the conus medullaris causes complete loss of anal skin reflex, bulbocavernosus reflex and all reflex response of the detrusor muscle to filling the bladder and to percussion in nearly all patients. I know of only one exception, other than the very common temporary appearance of reflexlike detrusor activity during urinary infections. The exception is a woman who had slight detrusor reflex activity at first cystometry after posterior rhizotomy at the conus medullaris. In the following 2 years this increased and caused incontinence.

\section{Permanence of the detrusor areflexia after S2-5 posterior rhizotomy}

I know of no observation contradicting the view that the detrusor areflexia following S2-5 posterior rhizotomy is permanent if it is achieved at all (as it nearly always is). Cystometrically verified detrusor areflexia after intentional posterior rhizotomy of S3 with probable unintentional posterior rhizotomy of S4 has lasted 9 years in patient 25 of reference 21 . Intentional $\mathrm{S} 2-5$ posterior rhizotomy was not done until $1986 .{ }^{17}$ All the four patients who had it done in that year were still areflexic at last follow up, 7, 7, 6 and 6 years later.

\section{Whether to cut posterior roots}

The benefits from cutting posterior roots are very great. If a woman with a complete spinal cord transection asks for implantation of a sacral anterior root stimulator without sacral posterior rhizotomy, I think she should be refused it on the ground that she has not understood the situation. Any consent that she may have given to implantation is therefore not informed consent.

A man with a complete lesion, or a man or woman with an incomplete lesion, who makes the same request, should be deferred to a later year if the centre where the request is made has little experience. Patients with sensory sparing and men with good reflex erections have something to lose by deafferentation, so their request is not a wholly unreasonable one. It is also not irrevocable; if it later becomes clear that posterior rhizotomy should have been done, and the patient then wants it, it can be done at the conus medullaris. However, the results of the implantation of a stimulator are much less good without than with posterior rhizotomy, and in a new centre it is important that the first few implantations should be fully successful. So patients willing to have posterior rhizotomy at the time of implantation should have priority.

\section{Extradural versus intrathecal electrodes}

The use of extradural electrodes with deafferentation at the ganglia is probably justified only when severe arachnoiditis leaves no alternative. ${ }^{27}$ The use, as a primary procedure, of extradural electrodes with deafferentation at the conus medullaris is the standard practise in Barcelona ${ }^{39}$ and Singapore. Its disadvantages are that the surgery involved is slightly more invasive and takes slightly longer, and that T12-L1 laminectomy is probably more risky for the stability of the vertebral column than L4-S2 laminectomy. The advantage of the Barcelona procedure is that the risk of anterior root damage is almost certainly lower. Time will tell whether it or the classical intrathecal implantation is better on balance.

\section{Appendix}

For answers to my questionnaire, and in many cases for additional information, I am indebted to the following, who are listed in the order of the number of patients for whom they provided information. 
Dr D Sauerwein, Werner-Wicker-Klinik, Bad Wildungen (114); Mr D G Thomas. Lodge Moor Hospital, Sheffield (33); Dr H Frankel and $\mathrm{Mr} \mathrm{B}$ Gardner, National Spinal Injuries Centre, Stoke Mandeville (31): Dr G Egon, Centre de l'Arche, Le Mans (30); Professor H Madersbacher, University Hospital, Innsbruck (22); Dr P van Kerrebroek, University Hospital, Nijmegen (17); Professor J Barat, Hopital Pellegrin, Bordeaux (14); Dr Alyson Grant, Rookwood Hospital, Cardiff (14); Dr F Noll, Verbandskrankenhaus, Schwelm (13); Dr H van der Aa, Ziekenhuis Enschede (13); Mr P Edmond, formerly Edinburgh, now Southern General Hospital Glasgow (11); Mr M Fraser, Regional Spinal Injuries Centre, Southport (10); Professor E Arnold, University Hospital, Christchurch, NZ (9); Mr D Grundy, Spinal Injuries Unit, Odstock (8); Dr R Richter, Zentralkrankenhaus Sankt-Jürgenstrasse, Bremen (8); Dr J Nordling, Herlev Hospital, Copenhagen (7); Dr A Gross, Universitätsklinikum Steglitz, Berlin (7); Dr F Ohanna, Propara,
Montpellier (6); Dr J Yeo, Royal North Shore Hospital, Sydney (6); Professor Sarrias, Institut Guttmann, Barcelona (5); Dr D Brown, Austin Hospital, Melbourne (5); Mr Timothy Lee, National University Hospital, Singapore (4); $\mathrm{Mr}$ R Bentley, Spinal Injuries Unit, Hexham (4); Dr H Burgdörfer, Berufsgenossenschaftliches Unfallkrankenhaus, Hamburg (4); Mr W G Loughridge, City Hospital, Belfast (3); Mr W el Masri, Midlands Spinal Injuries Centre, Oswestry (3); Professor J Wyndaele, formerly Gent, now University Hospital, Antwerp (3); Dr B Schurch, Swiss Paraplegic Centre Balgrist, Zürich (3); Dr C Hultling, Karolinska Hospital, Stockholm (2); Dr Lycklama, University Hospital, Leiden (2); Mr A I Low, Royal Perth Hospital, Western Australia (2); Dr S Harrison, Spinal Injuries Unit, Wakefield (1); $\mathrm{Dr}$ W Thon, Medizinische Hochschule Hannover (1); Dr A Bucziński, Metropolitan Rehabilitation Centre, Konstancin, Poland (1); Dr P Decq, Hopital Henri Mondor, Paris (1); Dr R Bosch, Akademisch Ziekenhuis, Rotterdam (1).

\section{References}

1 Brindley GS (1972) Electrode-arrays for making long-lasting electrical connexion to spinal roots. J Physiol (Lond) 222: 135-6P.

2 Brindley GS (1973) Emptying the bladder by stimulating sacral ventral roots. J Physiol (Lond) 237: 15-6P.

3 Brindley GS (1977) An implant to empty the bladder or close the urethra. J Neurol Neurosurg Psychiatry 40: $358-369$.

4 Schmidt RA, Bruschini H, Tanagho EA (1978) Feasibility of inducing micturition through chronic stimulation of spinal roots. Urology 12: 471-476.

5 Bazeed MA, Thüroff JW, Schmidt RA et al (1982) Effect of chronic electrostimulation of sacral roots on striated urethral sphincter. J Urol 128: 1357-1362.

6 Brindley GS, Polkey CE, Rushton DN (1982) Sacral anterior root stimulator for bladder control in paraplegia. Paraplegia 20: 365-381.

7 Tanagho EA, Schmidt RA, Orvis BR (1989) Neural stimulation for control of voiding dysfunction: a preliminary report in 22 patients with serious neuropathic voiding disorders. J Urol 142: 340-345.

8 Baskin LS, Schmidt RA (1992) Bladder rehabilitation with dorsal rhizotomy and ventral neuroprosthesis. Paraplegia 30: 783-787.

9 Cardozo L, Krishnan KR, Polkey CE et al (1984) Urodynamic observations on patients with sacral anterior root stimulators. Paraplegia 22: 201-209.

10 Brindley GS, Polkey CE, Rushton DN, Cardozo L (1986) Sacral anterior root stimulators for bladder control in paraplegia: the first 50 cases. J Neurol Neurosurg Psychiatry 49: 1104-1114.

11 Arnold EP, Gowland SP, MacFarlane MR et al (1986) Sacral anterior root stimulation of the bladder in paraplegics. Aust N Z J Surg 56: 319-324.

12 Varma JS, Binnie N, Smith AN et al (1986) Differential effects of sacral anterior root stimulation on anal sphincter and colorectal motility in spinally injured man. Br J Surg 73: 478-482.

13 Herlant M, Colombel P (1986) Electrostimulation intra-durale des racines sacrées antérieurs chez les paraplégiques. Historique, résultats, indications. Annales de Réadaptation et de Médecine Physique 29: 405-411.

14 Robinson LQ, Grant A, Weston P et al (1988) Experience with the Brindley anterior sacral root stimulator. Br J Urol 62: 553-557.

15 Brindley GS (1988) The actions of parasympathetic and sympathetic nerves in human micturition, erection and seminal emission, and their restoration in paraplegic patients by implanted electrical stimulators. Proc $R$ Soc London B 235: 111-120.

16 Madersbacher H, Fischer H, Ebner A (1988) Anterior sacral root stimulator (Brindley): experiences especially in women with neurogenic urinary incontinence. Neurourol Urodynamics 7: 593-601.

17 Sauerwein D (1988) Funktionelle Elektrostimulation der Harnblase: erste Erfahrungen mit sakraler Deafferentation und Vorderwurzelstimulation nach Brindley in Deutschland. Verh Dtsch Ges Urol 39: 595-597. 
18 Nordling J, Hald T, Kristensen JK et al (1988) Implanterbar radiostyretsakralrodstimulator til kontrolleret vandledning. Ugeskrift for Laeger 150: 978-980.

19 Egon G, Colombel P, des Roseaux F et al (1989) Electrostimulation des racines sacrées antérieures chez le paraplégique. A propos de 13 observations. Annales de Réadaptation et de Médecine Physique 32: 47-57.

20 Barat M, Egon G, Colombel P et al (1989) La neurostimulation sacrée dans le traitment des neuro-vessies centrales. Rencontre autour du Blessé Médullaire, pp 80-86. Paris: Masson.

21 Brindley GS, Rushton DN (1990) Long-term follow-up of patients with sacral anterior root stimulator implants. Paraplegia 28: 469-475.

22 MacDonagh RP, Sun WM, Smallwood R et al (1990) Control of defaecation in patients with spinal injuries by stimulation of sacral anterior nerve roots. BMJ 300: 1494-1497.

23 Brindley GS (1990) Treatment of urinary and faecal incontinence by surgically implanted devices. Neurobiology of Incontinence (Ciba Foundation Symposium): 267-282. Wiley, Chichester.

24 Sauerwein D (1990) Die operative Behandlung der spastischen Blasenlähmung bei Querschnittlähmung. Urologe (A) 29: 196-203.

25 MacDonagh RP, Forster DMC, Thomas DG (1990) Urinary continence in spinal injury patients following complete sacral posterior rhizotomy. Br J Urol 66: 618-622.

26 Binnie, NR, Smith, AN, Creasey, GH, Edmond P (1990) Motility effects of electrical anterior sacral nerve root stimulation of the parasympathetic supply of the left colon and ano-rectum in paraplegic subjects. J Gastrointest Motility 2: 12-17.

27 Sauerwein D, Ingunza W, Fischer J et al (1990) Extradural implantation of sacral anterior root stimulators. J Neurol Neurosurg Psychiatry 50: 681-684.

28 Binnie NR, Smith AN, Creasey GH, Edmond, P (1991) The effects of electrical anterior sacral nerve root stimulation on pelvic floor function in paraplegic subjects. J Gastrointest Motility 3: 39-45.

29 Binnie, NR, Smith, AN, Creasey, GH \& Edmond, P (1991) Constipation associated with chronic spinal cord injury: the effect of pelvic parasympathetic stimulation by the Brindley stimulator. Paraplegia 29: 463-469.

30 Colombel P, Egon G (1991) L'électrostimulation des racines sacrées anterieures. Annales d'Urologie 25: $48-52$.

31 van Kerrebroek PEV, Koldewijn E, Wijkstra H, Debruyne FMJ (1991) Intradural sacral rhizotomies and implantation of an anterior sacral root stimulator in the treatment of neurogenic bladder dysfunction after spinal cord injury. World J Urol 9: 126-132.

32 Barat M, Egon G, Daverat P et al (1992) Electrostimulation des racines sacrées antérieures dans le traitement des neuro-vessies centrales: résultats des 40 premiers cas francais. In: Pelissier J, editor. Rééducation Vésicosphinctérienne et Ano-rectale. Masson, Paris: 208-215.

33 Ohanna F, Costa P, Segniarbieux F et al (1992) Stimulation des racines antérieures sacrées et paraplégie: évolution des techniques et critères de sélection. In: Pelissier J, editor. Rééducation Vésicosphinctérienne et Ano-rectale. Masson, Paris: 208-215.

34 van Kerrebroek PEV, Koldewijn EL, Wijkstra H, Debruyne FMJ (1992) Urodynamic evaluation before and after intradural posterior rhizotomies and implantation of the Finetech-Brindley anterior sacral root stimulator. Urodinamica 1: 7-16.

35 Cardozo LD, Brindley GS (1992) Endoscopically guided bladder neck suspension for continence in paraplegic women with implant-driven micturition. Paraplegia 30: 336-338.

36 Madersbacher H, Fischer J (1993) Anterior sacral root stimulation and posterior sacral root rhizotomy. Akt Urol 24: 32-35.

37 Brindley GS (1993) Physiological considerations in the use of sacral anterior root stimulators. Neurourol Urodynamics 12: 485-486.

38 Madersbacher H, Fischer J (1993) Sacral anterior root stimulation: prerequisites and indications. Neurourol Urodynamics 12: 489-494.

39 Sarrias M, Sarrias F, Borau A (1993) The Barcelona technique. Neurourol Urodynamics 12: 495-496.

40 van Kerrebroek PEV, Koldewijn EL, Debruyne FMJ (1993) Worldwide experience with the FinetechBrindley sacral anterior root stimulator. Neurourol Urodynamics 12: 497-503.

41 Barat M, Egon G, Daverat P et al (1993) Why does continence fail after sacral anterior root stimulator? Neurourol Urodynamics 12: 507-508.

42 Egon G, Colombel P, Isambert J et al (1993) Evolution of bladder contraction in course of time after implantation of a sacral anterior root stimulator. Neurourol Urodynamics 12: 509-512.

43 Isambert J, Egon G, Colombel P (1993) Adjuvant drug therapy: a review of 30 cases of sacral anterior root stimulator. Neurourol Urodynamics 12: 513-515.

44 Barat M, Egon G, Daverat P et al (1993) L'électrostimulation des racines sacrées antérieurs dans le traitement des neuro-vessies centrales. J d'Urol 99: 3-7.

45 Creasey GH (1993) Electrical stimulation of sacral roots for micturition after spinal cord injury. Urol Clin $N$ Am 20: 505-515.

46 Brindley GS (in press) The first 500 sacral anterior root stimulators: implant failures and their repair. Paraplegia.

47 Van Kerrebroek PEV, Koldewijn EL, Rosier P et al (1994) Results of the treatment of neurogenic bladder dysfunction in spinal cord injury by sacral posterior root rhizotomy and anterior sacral root stimulation. 
Thesis, University of Nijmegen, Chapter 9.

48 Koldewijn EL, van Kerrebroek PEV, Rosier P et al (1994) Bladder compliance after posterior rhizotomies and anterior sacral root stimulation. J Urol 151: 955-960.

49 Brindley GS (1994) The Finetech-Brindley Bladder Controller: Notes for Surgeons and Physicians. Finetech, Welwyn Garden City. 